\title{
Susceptibility of diabetics with superoxide dismutase gene 2 polymorphism to cardiovascular complications
}

\author{
M. C. Archana 1,", Minu Meenakshi Devi K. R. ${ }^{2}$ \\ Assistant Professor, Dept. of Biochemistry, ${ }^{1}$ Government Medical College, Omandurar Government Estate, Chennai, Tamil \\ Nadu, ${ }^{2}$ Stanley Medical College, Chennai, Tamil Nadu, India
}

*Corresponding Author:

Email: sweetarchu1608@gmail.com

Received: $20^{\text {th }}$ October, 2017

Accepted: $11^{\text {th }}$ December, 2017

\begin{abstract}
Introduction: Diabetes mellitus is the most important cause for vascular diseases of heart and brain. The major factor in the development of diabetic complications is oxidative stress. Superoxide dismutases (SODs) are the enzymes which play a primary role against oxidative stress. A polymorphism C/T substitution producing TT genotype in superoxide dismutase 2 gene causes impaired targeting of the SOD 2 enzyme, resulting in reduced activity of the enzyme inside mitochondria. This can lead to increased oxidative stress in these patients making them susceptible to cardiovascular complications

Aim: Our study is performed to analyse if there is increased susceptibility of diabetics with SOD2 gene polymorphism to cardiovascular complications and to assess if this SOD2 polymorphism causes reduced SOD activity.

Materials and Methods: 30 cases of diabetics with cardiovascular disease, 30 cases of diabetics without cardiovascular disease and 30 healthy controls are included in the study. Genotype analysis by PCR and RFLP and serum superoxide dismutase activity is measured by spectrophotometer.

Results: TT genotype is more frequently distributed and Serum SOD activity is reduced among diabetics with CVD compared to diabetics without CVD and controls, which shows an increased risk of cardiovascular complications among diabetics with SOD2(GCT/GTT) gene polymorphism.

Conclusion: TT genotype is an independent risk factor for the development of cardiovascular complications in diabetes. Patients with TT genotype have reduced level of serum superoxide dismutase that may cause increased oxidative stress, the main mechanism for development of cardiovascular complications in diabetes.
\end{abstract}

Keywords: Diabetes, Cardiovascular disease, Oxidative stress, Superoxide dismutase 2 gene polymorphism.

\section{Introduction}

Diabetes mellitus is a major risk factor for cardiovascular disease. The combining factor in the development of diabetic complications is oxidative stress. ${ }^{1}$ Oxidized LDL results in atherosclerotic plaque ${ }^{2}$ formation that leads to vascular complications. It is a fact that among diabetics some develop vascular complications but not seen in others. This may be due to some gene polymorphism in those developing complications.

Gene polymorphisms in antioxidant enzymes like superoxide dismutase and catalase in diabetes has been reported. ${ }^{3}$ Polymorphism in antioxidant enzmes result in decrease in level and activity of antioxidant enzymes which leads on to oxidative stress. This increase in oxidative stress can lead on to atherothrombotic complications. A polymorphism in superoxide dismutase 2 gene which changes the secondary structure of mitochondrial targeting sequence of the manganese superoxide dismutase enzyme is seen. This polymorphism is present in exon 2 of the gene where normal GCT is mutated to GTT. This results in creation of a restriction site(rs 4880) as well as change of aminoacid from alanine to valine at $16^{\text {th }}$ position. This enzyme otherwise called as manganese superoxide dismutase is present inside mitochondria. This polymorphism in mitochondrial targeting sequence of the enzyme causes impaired targeting of the SOD 2 enzyme resulting in reduced activity of the enzyme inside mitochondria.

This study is done to find out if this polymorphism is associated with cardiovascular complications in diabetes, and to correlate it with superoxide dismutase activity.

\section{Materials and Methods}

This is a case-control study conducted after obtaining ethical committee clearance. This study was conducted at Madras Medical College and Rajiv Gandhi Government General Hospital, Chennai.

\section{Cases}

About 60 diabetic patients with more than five years duration attending cardiology ward, diabetology ward and outpatient department were included in the study after obtaining consent and were categorized into: Group 1A: 30 (14 males, 16 females) type 2 diabetic patients with cardiovascular disease and

Group 1B: 30 (11 males, 19 females) type 2 diabetic patients without cardiovascular disease.

The diagnosis is based on clinical history, fasting plasma glucose levels and ECG findings (pattern of 
myocardial infarction in case of Group 1A and normal pattern in case of Group 1B)

Exclusion criteria: Patients less than 30 years of age and less than 5 years of duration of diabetes.

\section{Controls :( Group 2)}

30 individuals attending master health check- up were selected as controls. Age, sex and other confounding factors like smoking, alcoholism were matched.

Blood was collected after an overnight fast of 8-12 hrs. About $4 \mathrm{~mL}$ of blood was drawn from the cubital vein of the subjects. $2 \mathrm{~mL}$ was transferred into a EDTA tubes and another $2 \mathrm{ml}$ transferred in to serum tube.

Serum superoxide dismutase activity, plasma triglycerides, plasma HDL, plasma cholesterol, plasma glucose, was analyzed by using kits in ERBA semiautoanalyser. Low density lipoprotein cholesterol (LDL-c) was calculated using Friedwald's formula.

DNA was extracted from buffy coat by high salt method $^{4}$ and was used to amplify the $267 \mathrm{bp}$ target region in the SOD2 gene by PCR using forward 5'GCTGTGCTTTCTCGTCTTCAG3 'and reverse 5'TGGTACTTCTCCTCGGTGACG3' primers

i. Genomic DNA $(1 \mu \mathrm{g})$ was amplified in $25 \mu \mathrm{l}$ reaction mixture containing $5 \mathrm{pmol} / \mu \mathrm{L}$ of each primer and Helini master mix containing $100 \mu \mathrm{mol} / \mathrm{L}$ of each $\mathrm{dNTP}, 2.5 \mu \mathrm{L}$ of $10 \mathrm{x}$ reaction buffer and 0.6 unit of Taq DNA polymerase. After the DNA was denatured for 5 minutes at $94^{\circ} \mathrm{C}$, the reaction mixture was subjected to 30 cycles of denaturation for one minute at $94^{\circ} \mathrm{C}, 1$ minute of annealing at $60^{\circ} \mathrm{C}$ and 1 minute of extension at $72^{\circ} \mathrm{C}$. Final extension was carried over at $72^{\circ} \mathrm{C}$ for 10 minutes.

ii. SOD2 polymorphism was detected by digestion of the PCR amplified product with the Bsaw1 restriction enzyme (5 units for overnight incubation at $60^{\circ} \mathrm{C}$ ). The digested products were separated by electrophoresis on a $2.5 \%$ agarose gel, and visualized under ultraviolet light after ethidium bromide staining.

iii. C allele in GCT codon does not have a restriction site and hence will yield a 267bp fragment.

iv. If $\mathrm{T}$ allele is present (GTT codon), a restriction site is created and so the PCR product gets cleaved to give $184 \mathrm{bp}$ and $83 \mathrm{bp}$ fragments.

v. Heterozygous individuals (CT genotype) will have 267bp, 184bp and 83bp fragments.

vi. Analysis was done using 100bp DNA ladder.

\section{Phenotype analysis:Estimation of serum superoxide} dismutase activity:

METHOD; Xanthine method, enzymatic method

Kit used- Fortress Diagnostics Limited Reference range: $164-240 \mathrm{U} / \mathrm{ml}$.

\section{Statistical analysis}

1. Age, BMI, Fasting plasma glucose, triglycerides, total cholesterol, LDL-cholesterol, HDL cholesterol were compared between the 3 study groups by ANOVA.

2. Duration of diabetes, hypertension, plasma glucose, plasma lipid profile were compared between group 1A (diabetes with CVD) and group 2(diabetes without CVD) by t test.

3. Smoking, alcoholism between 3 groups was compared by chi square test.

4. SOD Genotype frequency (TT, CT, and CC) distribution between cases and controls were compared with Chi square test.

5. 5 SOD activity was compared between the study groups by ANOVA.

6. SOD activity for MnSOD genotypes were compared by ANOVA.

\section{Results}

1. Age, BMI, Fasting lipid profile and plasma glucose were compared between the 3 study groups by ANOVA. Male and female sex, Smoking, alcoholism between 3 groups was compared by chi square test. (Table 1)

There is no significant difference between confounding factors like age, BMI, male sex, smoking, alcoholism, HDL cholesterol between groups.

There is significant difference in plasma glucose, triglycerides, total cholesterol, LDL-cholesterol between cases and controls.

2. Duration of diabetes, hypertension, plasma glucose, plasma lipid profile were compared between group 1A (diabetes with CVD) and group 1B (diabetes without CVD) by t test.

There is no significant difference in duration of diabetes, hypertension, plasma glucose, plasma lipid profile between group $1 \mathrm{~A}$ (diabetes with CVD) and group 1B (diabetes without CVD). (Table 2).

3. TT genotype is more frequently distributed among diabetics with CVD 20(66.7\%) compared to diabetics without CVD 11(36.7\%) and controls $1(3.3 \%)$. There was a significant difference in the distribution of TT genotype between diabetic CVD cases and the other two groups as indicated by the $\mathrm{P}$ value $(0.006)$.

$\mathrm{CT}$ and $\mathrm{CC}$ genotypes are distributed more in the diabetics without CVD and in controls when compared to diabetics with CVD population. (Table 3)

4. It is found that serum SOD activity for group $1 \mathrm{~A}$ (diabetics with CVD) was $85 \mathrm{U} / \mathrm{L}$ while that of group 1B (diabetics without CVD) was 127U/L and that of controls was 165U/L.(Fig. 1) 
$\mathrm{P}$ value is 0.000 , indicates that the difference is statistically significant.

The SOD activity of Group 1B (diabetic without CVD) and Control are within the normal range but that of Group 1 (diabetic CVD) is well reduced below lower limit of normal. (Table 4)

5. The association of SOD genotype with the phenotype (SOD activity) is shown (Fig. 2). It is observed that serum SOD activity is reduced in TT genotype. Reduced (85U/L) level of SOD activity in TT genotype, highest (184U/L) in CC genotype and intermediate (144U/L) in CT genotype..P value $=0.000$ which is highly significant statistically. (Table 5)

Table 1: Comparison of demographic data, lab parameters, smoking, alcoholism in diabetics with CVD, diabetics without CVD and Control

\begin{tabular}{|l|l|l|l|c|c|}
\hline \multirow{2}{*}{ Variables } & \multicolumn{2}{c|}{ Cases } & \multirow{2}{*}{$\begin{array}{c}\text { Controls } \\
\text { Group 2 }\end{array}$} & P-Value & Results \\
\cline { 2 - 5 } & $\begin{array}{c}\text { Group1A DM } \\
\text { with CVD }\end{array}$ & $\begin{array}{c}\text { Group 1B DM } \\
\text { without CVD }\end{array}$ & & \\
\hline Age(years) & $52.67 \pm 7.586$ & $55.27 \pm 8.263$ & $55.27 \pm 8.103$ & 0.351 & NS \\
\hline BMI & $27.19 \pm 2.557$ & $26.06 \pm 3.424$ & $26.24 \pm 2.638$ & 0.273 & NS. \\
\hline $\begin{array}{l}\text { Fasting plasma glucose } \\
\text { (mg/dL) }\end{array}$ & $156.10 \pm 39.270$ & $158.60 \pm 41.199$ & $91.27 \pm 4.160$ & 0.000 & S \\
\hline Cholesterol (mg/dL) & $192.93 \pm 40.56$ & $191.57 \pm 38.421$ & $152.10 \pm 11.158$ & 0.000 & S \\
\hline TGL (mg/dL) & $162.67 \pm 41.7$ & $166.57 \pm 43.602$ & $126.87 \pm 22.685$ & 0.000 & S \\
\hline HDL (mg/dL) & $60.22 \pm 10.854$ & $62.8 \pm 10.545$ & $63.367 \pm 9.661$ & 0.459 & NS \\
\hline LDL(mg/dL) & $100.18 \pm 39.865$ & $95.45 \pm 38.846$ & $63.36 \pm 12.192$ & 0.000 & S \\
\hline Duration of DM(years) & $5.47 \pm 1.432$ & $5.37 \pm 1.426$ & & 0.787 & NS \\
\hline Hypertension & $16(51.6 \%)$ & $15(48.4 \%)$ & & 0.796 & NS \\
\hline Sex-Male & $18(32.1 \%)$ & $19(33.9 \%)$ & $19(33.9 \%)$ & 0.954 & NS \\
\hline Sex-Female & $12(35.3 \%)$ & $11(32.4 \%)$ & $11(32.4 \%)$ & 0.954 & NS \\
\hline Smoking & $13(37.1 \%)$ & $11(31.4 \%)$ & $11(31.4 \%)$ & 0.829 & NS \\
\hline Alcoholism & $10(33.3 \%)$ & $10(33.3 \%)$ & $10(33.3 \%)$ & 1.000 & NS \\
\hline
\end{tabular}

NS- not significant, $\mathbf{S}$ - Significant

Table 2: Comparison of Fasting plasma glucose, lipid profile, duration of diabetes between diabetics with CVD and group diabetics without CVD

\begin{tabular}{|l|c|c|c|c|}
\hline \multirow{2}{*}{ Variables } & \multicolumn{2}{c|}{ Cases } & \multirow{2}{*}{ P-Value } & \multirow{2}{*}{ Results } \\
\cline { 2 - 3 } & $\begin{array}{c}\text { Group1A DM } \\
\text { with CVD }\end{array}$ & $\begin{array}{c}\text { Group 1B DM } \\
\text { without CVD }\end{array}$ & \\
\hline $\begin{array}{l}\text { Fasting plasma glucose } \\
\text { (mg/dL) }\end{array}$ & $156.10 \pm 39.270$ & $158.60 \pm 41.199$ & 0.810 & NS \\
\hline Cholesterol (mg/dL) & $192.93 \pm 40.56$ & $191.57 \pm 38.421$ & 0.893 & NS \\
\hline TGL (mg/dL) & $162.67 \pm 41.7$ & $166.57 \pm 43.602$ & 0.724 & NS \\
\hline HDL (mg/dL) & $60.22 \pm 10.854$ & $62.8 \pm 10.545$ & 0.354 & NS \\
\hline LDL( mg/dL) & $100.18 \pm 39.865$ & $95.45 \pm 38.846$ & 0.643 & NS \\
\hline Duration of DM(years) & $5.47 \pm 1.432$ & $5.37 \pm 1.426$ & 0.787 & NS \\
\hline Hypertension & $16(51.6 \%)$ & $15(48.4 \%)$ & 0.796 & NS \\
\hline
\end{tabular}

Table 3: SOD 2 genotype distribution in study population

\begin{tabular}{|c|c|c|c|c|}
\hline Genotype & $\begin{array}{c}\text { Group1A } \\
\text { DM with CVD 30 }\end{array}$ & $\begin{array}{c}\text { Group1B } \\
\text { DM without } \\
\text { CVD 30 }\end{array}$ & $\begin{array}{c}\text { Group 2 } \\
\text { Controls 30 }\end{array}$ & \multirow{2}{*}{ P value } \\
\cline { 1 - 4 } TT & $20(66.7 \%)$ & $11(36.7 \%)$ & $7(23.3 \%)$ & \multirow{2}{*}{$0.006-\mathrm{S}$} \\
\cline { 1 - 4 } CT & $9(30.0 \%)$ & $13(43.3 \%)$ & $14(46.7 \%)$ & \\
\hline CC & $1(3.3 \%)$ & $6(20.0 \%)$ & $9(30.0 \%)$ & \\
\cline { 1 - 3 }
\end{tabular}

Table 4: Serum SOD activity between study groups

\begin{tabular}{|l|l|c|c|c|}
\hline & $\begin{array}{c}\text { Group 1A } \\
\text { DM with CVD }\end{array}$ & $\begin{array}{c}\text { Group 1B } \\
\text { DM without } \\
\text { CVD }\end{array}$ & $\begin{array}{c}\text { Group 2 } \\
\text { Conrtol }\end{array}$ & P value \\
\hline $\begin{array}{l}\text { Serum SOD } \\
\text { activity U/L }\end{array}$ & $85.60 \pm 34.843$ & $127.70 \pm 34.771$ & $165.43 \pm 43.792$ & $0.000-\mathrm{S}$ \\
\hline
\end{tabular}




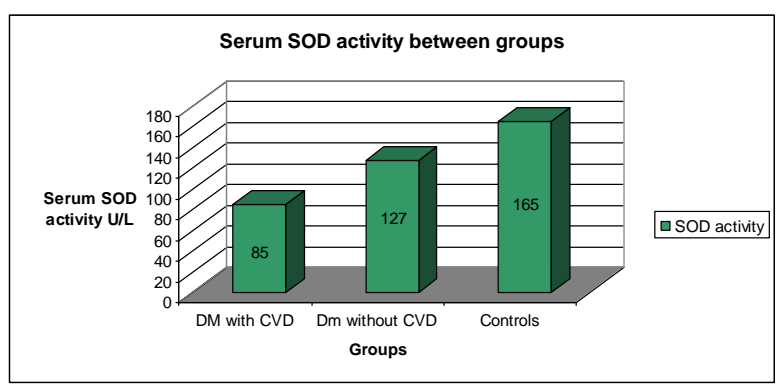

Fig. 1: Serum SOD activity between diabetics with and without CVD and controls

Table 5: Genotype and Phenotype (SOD activity)

\begin{tabular}{|c|l|l|}
\hline Genotype & SOD activity(U/L) & P value \\
\hline TT & $85.13 \pm 33.228$ & \multirow{2}{*}{$0.000-\mathrm{S}$} \\
\hline CT & $143.92 \pm 31.115$ & \\
\hline CC & $184.12 \pm 34.415$ & \\
\hline
\end{tabular}

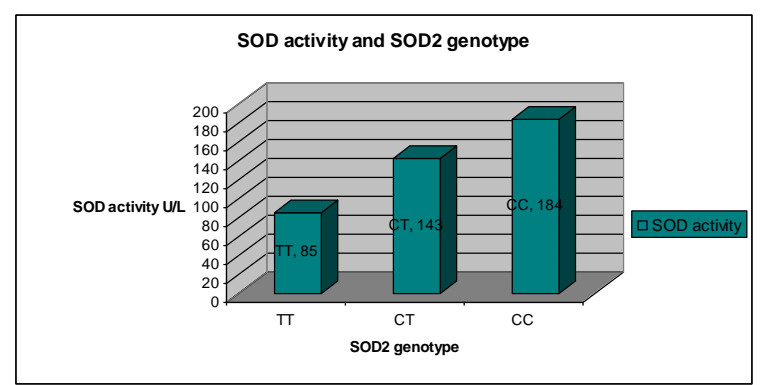

Fig 2: Comparison between SOD activity and SOD2 genotype

\section{Discussion}

Hyperglycemia and increased free fatty levels in diabetes causes elevated superoxide production in mitochondria which is the major mechanism in development of cardiovascular complications. This mitochondrial superoxide is normally destroyed by mitochondrial superoxide dismutase. The hypothesis in this study is that polymorphism in mitochondrial targeting sequence of manganese superoxide dismutase gene causes reuced superoxide dismutase activity which causes increased superoxide level inside mitochondria.This increased superoxide level accelerates the development of cardiovascular complications.

The polymorphism in SOD2 gene causes mutation of GCT codon to GTT which results in conversion of aminoacid alanine to valine. So normal individuals have CC genotype and those with polymorphism have TT genotype. From our study we found a more frequent association of TT (val/val) genotype in diabetics with cardiovascular complications (66.7\%) when compared to controls (3.3\%) and type 2 diabetics without cardiovascular Complications (36.7\%). The Odds ratio between diabetics with cardiovascular complications and diabetics without cardiovascular complications was found to be 3.45 in our study. Also $\mathrm{T}+$ allele is more common in diabetic CVD cases $(97 \%)$ when compared to controls $(70 \%)$. The odds ratio was found to be 12 and $p$ value $(0.015)$ also significant.

This is similar to the study done by Milan Flekac et al, who found positive association between the $\mathrm{T}$ allele of the MnSOD gene polymorphism and diabetic cardiovascular complications in Prague, Czech Republic.

There are no significant differences in confounding factors like age, sex, BMI, smoking, alcoholism, hypertension, plasma triglycerides, LDL-cholesterol between diabetics with cardiovascular complications and diabetics without cardiovascular complications.

In our study we found that serum superoxide dismutase activity was reduced in the diabetics with cardiovascular complications, with the mean value of $85 \mathrm{U} / \mathrm{L}$ while that of diabetics without cardiovascular complications group, it was $127 \mathrm{U} / \mathrm{L}$ and that of controls was $165 \mathrm{U} / \mathrm{L}$. The difference was found to be statistically significant $(\mathrm{P}$ value $=0.000)$ between diabetics with and without cardiovascular complications and between cases and controls.

We found that individuals with TT (val/val) genotype have lower serum superoxide dismutase activity than those with CC (ala/ala) and CT (ala/val) genotype. This may be due to alteration of conformation of mitochondrial targeting sequence from $\alpha$ helix (present in those with $\mathrm{C}$ allele) to $\beta$ sheets (present in those with $\mathrm{T}$ allele) which leads to reduced import of MnSOD enzyme in to mitochondria and degradation by proteasome., ${ }^{4,5}$ Similar findings were found by Hirori et $\mathrm{al}^{4} 158$ and Robert C.G. Martin et $\mathrm{al}^{5}$. These studies indicate that $\mathrm{T}$ (val) allele is associated with oxidative stress whereas $\mathrm{C}$ (Ala) allele protects against oxidative stress.

Dimitry A Chistyakov et al showed that Ala (9)Val substitution in the Mn SOD gene was associated with diabetic nephropathy in a Russian Population. This polymorphism has also been associated with diabetic nephropathy in Japanese and Korean patients with type 2 diabetes. ${ }^{6,7}$ Study done by Jones DA showed that TT genotype of this variant is associated with increased CHD risk and lower plasma anti-oxidant defences in females with diabetes in Caucasian subjects. ${ }^{8}$

In our study we found increased frequency of TT genotype and reduced level of serum superoxide dismutase activity in diabetic patients with cardiovascular complications.

\section{Conclusion}

Type 2 diabetics with cardiovascular disease had a higher frequency of SOD2 TT genotype compared to diabetics without cardiovascular disease and controls.

Serum SOD activity is significantly reduced in Diabetics with cardiovascular disease with TT genotype 
which may be responsible for cardiovascular complications.

TT genotype is an independent risk factor for the development of cardiovascular complications in diabetes.

\section{Future Prospects}

Research aimed at increasing the superoxide dismutase activity inside mitochondria by targeted drug delivery may be performed.

Trails of SOD mimetic compounds to diabetic patients and their follow up for development of complications may be tried.

\section{References}

1. Betsy B. Dokken, PhD, NP, CDE . The Pathophysiology of Cardiovascular Disease and Diabetes: Beyond Blood Pressure and Lipids. Diabetes Spectrum July 2008 vol. 21 no. 3,160-165.

2. Goldstein JL, Ho YK, Basu SK, Brown MS. Binding site on macrophages that mediates uptake and degradation of acetylated low density lipoprotein, producing massive cholesterol deposition. Proc Natl Acad Sci U S A 1979;76:333-7. [PubMed: 218198].

3. Milan Flekac*, Jan Skrha, Jirina Hilgertova, Zdena Lacinova and Marcela Jarolimkova Gene polymorphisms of superoxide dismutases and catalase in diabetes mellitus 21 April 2008 BMC Medical Genetics 2008.

4. Hiroi, SaHrada H, isNhi, HSatoh M, aNgai, RKimura A Polymorphisms in the SOD2 and HLA-DRB1 genes are associated with nonfamilial idiopathic dilated cardiomyopathy in Japanese. Biochem Biophys Res Commun 1999,261:332-9.

5. Robert C.G. Martin,1,2 Yan Li,1 Qiahong Liu,1 Neil S. Jensen,3 David F. Barker,2 Mark A. Doll,2 Manganese Superoxide Dismutase V16A Single-Nucleotide Polymorphism in the Mitochondrial Targeting Sequence Is Associated with Reduced Enzymatic Activity in Cryopreserved Human Hepatocytes. DNA AND CELL BIOLOGY Volume 28, Number 1, 2009.

6. Nomiyama T, Tanaka Y, Piao L, Nagasaka K, Sakai K, Ogihara T, Nakajima K: The polymorphism of manganese superoxide dismutase is associated with diabetic nephropathy in Japanese type 2 diabetic patients. J Hum Genet 48:138 -41, 2003.

7. Lee SJ, Choi MG, Kim DS, and Kim TW: Manganese superoxide dismutase gene polymorphism (V16A) is associated with stages of albuminuria in Korean type 2 diabetic patients. Metabolism 55:1-7, 2006.

8. Jones DA, Prior SL, Tang TS, Bain SC, Hurel SJ, Humphries SE Association between the rs 4880 superoxide dismutase $2(\mathrm{C}>\mathrm{T})$ gene variant and coronary heart disease in diabetes mellitus. Diabetes Res Clin Pract. 2010 Nov;90(2):196-201. 